\title{
ANALISIS KEUNTUNGAN FINANSIAL USAHA PENGGEMUKAN SAPI POTONG DI KABUPATEN BOJONEGORO
}

\author{
Retna D Lestari 1), Lukman M. Baga2), dan Rita Nurmalina2) \\ 1) Mahasiswa Pascasarjana Magister Sains Agribisnis, FEM, Institut Pertanian Bogor \\ 2) Staf Pengajar Departemen Agribisnis, FEM, Institut Pertanian Bogor \\ Email : bundo117@gmail.com Telp.081297219460
}

\begin{abstract}
Cattle farm agribusiness in Indonesia is still a sector that needs to be developed, given the increasing demand for meat, but has not met from domestic meat production. One of the efforts to achieve stability availability of beef that is through an increase in beef cattle fattening which have long-term prospects. This study aims to identify and analyze the financial benefits fattening beef cattle in Bojonegoro which is one of the central areas of the cow kind Peranakan Ongole $(P O)$ in the province of East Java. Data were analyzed quantitatively by using indicators of profitability and feasibility ie B / C Ratio, Break Even Point, Net Present Value, Internal Rate of Return, and Payback Period. The research location in the village Napis, District Tambakrejo with 30 respondents breeders who do fattening for 4 months. The results showed the average value of $B / C$ ratio of 1.23, NPV of USD 481 110, 59, IRR 11.30\%, and PBP for 2 years and 9 months. Based on the research results can be suggested to the Government of Bojonegoro in order to provide guidance and directs farmers to conduct fattening cattle given the small number of farmers who cultivate the cow on a large scale.
\end{abstract}

Keywords : Benefit, Finance, Beef Cattle Fattening, Agribusiness

\begin{abstract}
Abstrak : Usaha agribisnis peternakan sapi di Indonesia masih menjadi sektor yang perlu dikembangkan, mengingat akan kebutuhan daging yang semakin meningkat, namun belum terpenuhi dari produksi daging dalam negeri. Salah satu usaha mencapai stabilitas ketersediaan daging sapi yaitu melalui peningkatan usaha penggemukan sapi potong yang memiliki prospek jangka panjang. Penelitian ini bertujuan untuk mengetahui dan menganalisis tingkat keuntungan finansial usaha penggemukan sapi potong di Kabupaten Bojonegoro yang merupakan salah satu daerah sentra sapi jenis Peranakan Ongole (PO) di Provinsi Jawa Timur. Data dianalisis secara kuantitatif dengan menggunakan indikator keuntungan dan kelayakan usaha yaitu B/C Ratio, Break Even Point, Net Present Value, Internal Rate of Return, dan Pay Back Periode. Lokasi penelitian di Desa Napis, Kecamatan Tambakrejo dengan 30 responden peternak yang melakukan penggemukan selama 4 bulan. Hasil penelitian menunjukan nilai rata-rata B/C Ratio 1,23, nilai NPV sebesar Rp 481.110, 59, nilai IRR 11,30\%, dan PBP selama 2 tahun 9 bulan. Berdasarkan hasil penelitian dapat disarankan kepada Pemerintah Kabupaten Bojonegoro agar melakukan pendampingan dan mengarahkan peternak untuk melakukan usaha penggemukan sapi mengingat masih sedikitnya peternak yang mengusahakan sapinya dalam skala besar.
\end{abstract}

Kata kunci : Keuntungan, Finansial, Penggemukan Sapi Potong, Agribisnis

\section{PENDAHULUAN}

Sektor peternakan khususnya sapi potong di Indonesia telah lama menjadi usaha rakyat baik sebagai usaha utama maupun sampingan selain usaha bercocok tanam. Berdasarkan data Ditjennak (Direktorat Jenderal Peternakan dan Kesehatan Hewan, 2014), populasi sapi potong 
skala usaha peternakan rakyat mengalami peningkatan mulai tahun 2007 sampai tahun 2013 sebesar 3,188 juta ekor. Hal ini menunjukan bahwa usaha peternakan masih menjadi alternatif pilihan mata pencaharian penduduk Indonesia, dan berpotensi untuk terus dikembangkan, karena didukung adanya sumber daya alam yang berlimpah, seperti untuk pakan dan daya dukung dari segi iklim tropis yang cocok untuk peternakan sapi.

Walaupun didukung dengan keadaan iklim yang cocok, dari segi produksi dan konsumsi daging sapi yang semakin meningkat dengan pertambahan penduduk, Indonesia masih harus mengimpor daging sapi maupun sapi hidup dari negara lain seperti Australia. Salah satu usaha mencapai stabilitas ketersediaan daging sapi yaitu melalui peningkatan usaha penggemukan sapi potong yang memiliki prospek jangka panjang. Peternakan sapi potong rakyat di Indonesia sebagian besar masih merupakan usaha sambilan atau pelengkap usaha penggemukan dengan karakteristik utama jumlah ternak yang diperlihara sangat terbatas dan masukan (input) teknologi yang rendah. Skala usaha ternak sapi potong umumnya antara 1 sampai 4 ekor per rumah tangga peternak sapi potong (Widiyazid et al., 1999). Pada tingkat pemeliharaan minimum 6 ekor per rumah tangga sudah dapat dikategorikan pada usaha peternakan sapi potong skala kecil, yaitu usaha ternak sapi potong yang telah mulai berorientasi ekonomi. Pada skala tersebut perhitungan keuntungan dan masukan teknologi sudah mulai diterapkan walaupun masih sangat sederhana (Rochadi et al., 1993). Namun diharapkan usaha peternakan rakyat ini mampu untuk memenuhi kebutuhan daging sapi dalam negeri, mengingat potensi lingkungan yang mendukung.

Kecamatan Tambakrejo, Kabupaten Bojonegoro merupakan salah satu daerah sentra populasi sapi potong di Jawa Timur. Populasi sapi potong di Kecamatan Tambakrejo pada tahun 2013 adalah 14.784 ekor. Usaha peternakan sapi potong di Kecamatan Tambakrejo didukung dengan ketersediaan pakan yang memadai seperti rumput gajah, tebon, dan jerami, serta merupakan daerah yang berada dalam kawasan aliran sungai Bengawan Solo yang memungkinkan ketersediaan pakan yang melimpah. Dengan banyaknya populasi dan usaha ternak rakyat di Kecamatan
Tambakrejo, Kabupaten Bojonegoro maka perlunya analisis usaha apakah usaha ternak tersebut layak untuk di usahakan.

Analisis usaha kelayakan sapi potong sangat penting untuk dilakukan, agar kedepannya usaha yang dijalankan tidak mengalami kegagalan dan merupakan alat ukur apakah usaha sapi potong memberikan keuntungan yang berjangka panjang bagi peternak. Peternakan sapi potong merupakan peternakan yang paling banyak diusahakan, oleh karena itu diharapkan dapat memberikan kontribusi dalam peningkatan kesejahteraan peternak.

Tujuan dari penelitian ini adalah untuk mengetahui dan menganalisis tingkat keuntungan finansial usaha penggemukan sapi potong di Kabupaten Bojonegoro yang merupakan salah satu daerah sentra sapi jenis Peranakan Ongole (PO) di Provinsi Jawa Timur.

\section{METODE PENELITIAN}

Penelitian ini dilaksanakan di Desa Napis, Kecamatan Tambakrejo, Kabupaten Bojonegoro, yang berlangsung mulai bulan Januari sampai dengan Februari 2015. Lokasi penelitian ditentukan dengan purposive dengan pertimbangan bahwa Kecamatan Tambakrejo merupakan sentra populasi sapi potong terbesar di Kabupaten Bojonegoro. Pemilihan Desa Napis sebagai lokasi penelitian dengan pertimbangan bahwa populasi sapi potong di Desa Napis terbesar dibandingkan dengan desa lainnya di Kecamatan Tambakrejo.

Sampel responden dalam penelitian ini adalah 30 peternak sapi potong yang melakukan usaha penggemukan selama 4 bulan. Teknik pengumpulan data yang dilakukan dengan observasi langsung, serta wawancara peternak dengan menggunakan daftar pertanyaan (kuesioner). Jenis data yang digunakan adalah cross section tahun 2014, yang mana peternak terakhir menjual hasil ternaknya. Penelitian ini menggunakan dua macam data yang terdiri dari data primer dan sekunder. Data primer meliputi data identitas peternak, penerimaan yang diterima dari penjualan sapi potong, data komponen biaya seperti tenaga kerja, pakan, vitamin, obatobatan, biaya penyusutan dan biaya lainnya. Data sekunder yang diperoleh dari Badan Pusat 
Statitistik, Kecamatan Tambakrejo, dan Dinas Peternakan Kabupaten Bojonegoro.

Definisi operasional penelitian ini adalah sebagai berikut :

1. Sistem penggemukan sapi adalah usaha pemeliharaan ternak dengan cara mengandangkan secara terus-menerus

2. selama periode tertentu yang bertujuan meningkatkan produksi daging dengan mutu yang lebih baik sebelum ternak dipotong.

3. Periode penggemukan selama 4 bulan, diasumsikan setahun 2 kali masa penggemukan dengan periode 4 bulan untuk pengosongan kandang.

4. Perhitungan periode investasi dilakukan hingga 5 tahun.

5. Penerimaan diperoleh dari penjualan sapi selama satu tahun.

6. Harga input dan output dihitung berdasarkan harga yang berlaku di daerah penelitian dan dianggap tetap.

7. Unit analisis adalah satuan yang digunakan dalam analisis kelayakan usaha yang mengacu pada unit per ternak per tahun.

8. Discount factor yang digunakan dalam perhitungan adalah $10 \%$. Tingkat diskonto yang digunakan di Indonesia biasanya berkisar antara 10-15\% (Gray et al, 2005).

Layak tidaknya suatu usaha yang akan dilaksanakan dapat dilihat dari analisis kelayakannya. Beberapa parameter yang dapat dipergunakan untuk melihat kelayakan suatu usaha umumnya adalah analisis rasio B/C, payback period (PBP), dan analisis titik impas atau break even point (BEP), selain itu, akan lebih baik jika dilengkapi dengan perhitungan net present value (NPV), dan internal rate of return (IRR). Usaha sapi potong dikategorikan layak diusahakan apabila hasil analisis menunjukkan nilai BCR $>1$, NPV Positif, dan IRR lebih besar dari tingkat diskonto.

Rumusan analisis yang digunakan adalah :

a. Benefit Cost Ratio

Analisis benefit cost ratio (B/C) digunakan untuk melihat tingkat keuntungan atau penerimaan relatif suatu usaha dalam setahun terhadap total biaya keuntungan atau penerimaan relatif suatu usaha dalam setahun terhadap total biaya yang dipergunakan dalam kegiatan tersebut, dengan rumus sebagai berikut.

$$
B C R=\sum_{t=i}^{n} \frac{B t(1+i)^{i}}{C t(1+i)^{i}}
$$

(Kadariah et al, 1999)

\section{b. Break Even Point (BEP)}

Analisis break even point (BEP) dipergunakan untuk melihat batas nilai atau volume produksi dari suatu usaha. dengan perhitungan sebagai berikut.

$$
B E P(\text { Unit })=\frac{\text { biaya tetap }}{\text { harga jual/unit }- \text { biaya variabel/unit }}
$$

$$
B E P(R p)=\frac{\text { biaya tetap }}{1-\frac{\text { biaya variabel }}{\text { penjualan }}}
$$

(Halim, 2009)

\section{c. Pay back Periode (PBP)}

Analisis payback periode (PBP) dipergunakan untuk mengetahui lamanya pengembalian modal yang telah diinvestasikan dalam suatu usaha, dengan perhitungan sebagai berikut :

Payback Periode $=\frac{I}{A b}$

$\mathrm{I}$ = besarnya biaya investasi yang diperlukan, $\mathrm{Ab}=$ manfaat bersih yang dapat diperoleh pada setiap tahunnya

(Jumingan, 2009)

d. Net Present Value (NPV)

$$
N P V=\sum_{t=0}^{n} \frac{B t-C t}{(1+i)^{t}}
$$

(Kadariah et al, 1999)

Pada perhitungan NPV, semua proyeksi cash flow dikonversi menjadi suatu nilai ekuivalen pada tahun ke nol dengan menggunakan teknik discounting.

$\mathrm{Bt}=$ Keuntungan kotor yang diperoleh pada tahun $\mathrm{t}$ (benefit obtained in $\mathrm{t}$ year) 

$\mathrm{Ct}$ = Biaya yang dikeluarkan pada tahun $\mathrm{t}$ (cost being spent in t year )
$\mathrm{I}=$ Tingkat discount factor $(10 \%)$

e. IRR

$$
I R R=i+\frac{N P V}{\left(N P V+N P V^{\prime}\right)}\left(\mathrm{i}^{\prime}-\mathrm{i}\right)
$$

(Kadariah et al, 1999)

IRR didefinisikan sebagai discount rate yang menghasilkan nilai NPV sama dengan nol.

Keterangan :

IRR = tingkat discount yang akan dicari (discount factor)

NPV' = NPV dari discount factor yang rendah

NPV" = NPV dari discount factor yang tinggi

i" = discount factor yang rendah (lower discount factor)

i' = discount factor yang tinggi (higher discount factor)

\section{HASIL DAN PEMBAHASAN}

\section{Identitas Responden}

Berdasarkan hasil penelitian umur peternak dengan kisaran 44 tahun yang merupakan kisaran angka produktif. Tingkat pendidikan peternak di Desa Napis yang berpendidikan SMA (Sekolah Menengah Atas) sebanyak 2 orang $(6,67 \%$ ), tamat SMP (Sekolah Menengah Pertama) sebanyak 4 orang (13,33\%), tamat Sekolah Dasar (SD) terbesar yaitu 13 orang $(43,33 \%)$, dan responden yang tidak tamat SD ada 11 orang $(36,67)$. Hal ini menunjukkan bahwa pendidikan peternak masih rendah, pendidikan terkait dengan pola berpikir peternak.

Mata pencaharian utama responden sebagian besar adalah petani yaitu sebanyak 22 orang $(73,33 \%)$, pedagang yaitu sebanyak 4 orang $(13,33 \%)$, yang bermata pencaharian sebagai tukang kayu sebanyak 2 orang $(6,67 \%)$, dan yang berprofesi sebagai PNS dan karyawan koperasi masing-masing ada 1 orang

$(6,67 \%)$. Sedangkan jumlah anggota keluarga yang ditanggung peternak rata-rata adalah 3 anggota keluarga.

Pengalaman berternak responden dalam kisaran 13 tahun. Hal ini menunjukan bahwa usaha peternakan sapi potong ini merupakan usaha turun menurun yang sudah sejak lama ada, walaupun hanya sebagai usaha sampingan, beternak menjadi pilihan usaha yang menjadi tumpuan utama ketika ada kebutuhan yang mendesak dan juga sebagai tabungan maupun investasi responden di Desa Napis.

\section{Outflow Usaha Penggemukan Sapi Potong}

Biaya adalah segala sesuatu yang diinvestasikan, baik berupa uang, tanah dan bangunan, tenaga kerja, serta aset-aset lainnya yang diperlukan dalam proses produksi untuk menghasilkan suatu produk tertentu. Biaya tersebut dikeluarkan secara kontan (cash) atau kredit. Besaran biaya yang dikeluarkan dalam proses produksi akan menjadi acuan dalam penentuan harga pokok penjualan dan akan mempengaruhi kelayakan usaha.

Biaya yang dikeluarkan oleh peternak terdiri dari biaya tetap dan biaya variabel. Biaya tetap terdiri dari biaya investasi dan modal. Biaya Investasi terdiri dari biaya pembuatan kandang dan biaya pembelian peralatan, sedangkan dalam modal terdapat bunga dalam angsuran yang harus di bayarkan oleh peternak jika peternak tersebut meminjam modal dari bank maupun koperasi. Di Desa hampir seluruh peternak yang menjadi responden mengambil kredit dari Koperasi Lembu Seto sebagai modal dalam menjalankan usaha penggemukan sapinya. Biaya tetap ratarata peternak di Desa Napis adalah Rp 473.159,98.

Peralatan yang digunakan oleh peternak diantaranya adalah cangkul seharga Rp 50.000, sekrop seharga Rp 20.000, sabit dengan harga $\mathrm{Rp} 25.000$, keranjang dengan harga Rp 10.000, pengki bambu dengan harga Rp 5.000, dan karung dengan harga Rp 500. Umur pemakaian cangkul, sekrop, dan sabit adalah 2 tahun, sedangkan untuk keranjang, karung, dan pengki umur pakainya 1 tahun.

Biaya variabel rata-rata yang dikeluarkan oleh peternak adalah $\mathrm{Rp}$ 14.603.033,33/tahun. Biaya variabel terdiri dari biaya pakan, biaya kesehatan, biaya transportasi, biaya tenaga kerja, biaya pajak bumi dan bangunan (Tabel 1). Biaya pakan yang dibeli adalah dedak, dengan harga $\mathrm{Rp}$ $2500 / \mathrm{kg}$, namun ada beberapa peternak yang mempunyai gabah kemudian digiling, sisanya dalam bentuk dedak untuk pakan sapi jadi tidak beli, hanya mengeluarkan biaya selep sebesar 
Tabel 1. Inflow dan Outflow Usaha Penggemukan Sapi Potong di Desa Napis, Kecamatan Tambakrejo, Kabupaten Bojonegoro selama masa investasi 5 tahun

\begin{tabular}{|c|c|c|c|c|c|}
\hline \multirow[t]{2}{*}{ Uraian } & \multicolumn{5}{|c|}{ Tahun ke } \\
\hline & I & II & III & IV & V \\
\hline $\begin{array}{l}\text { I. Inflow } \\
\text { - Rata-Rata Penjualan } \\
\text { Ternak } \\
\text { (Rp/Tahun/peternak) }\end{array}$ & $18.586 .666,67$ & $19.266 .666,67$ & $19.946 .666,67$ & $20.656 .666,67$ & $21.378 .666,67$ \\
\hline Total Inflow & 18.586.666,67 & $19.266 .666,67$ & $19.946 .666,67$ & $20.656 .666,67$ & 21.378.666,67 \\
\hline II. Outflow & & & & & \\
\hline - Pembuatan Kandang & & & - & - & - \\
\hline - Pembelian peralatan & 3.500 .000 & - & - & - & - \\
\hline (cangkul, sabit, pengki, & 3.000 .000 & - & & & \\
\hline karung, dll) & & & & & \\
\hline - Sumber Air & 5.000 .000 & - & & & \\
\hline $\begin{array}{l}\text { - Lain-Lain } \\
\text { h Biava Tetan. }\end{array}$ & 2.500 .000 & & & & \\
\hline $\begin{array}{l}\text { b. Biaya Tetap : } \\
\text { - Penyusutan Kandang }\end{array}$ & & & & & \\
\hline & $186.202,54$ & $196.202,54$ & $199.202,54$ & $204.200,54$ & $186.202,54$ \\
\hline c. Biaya Variabel : & $286.957,46$ & $286.957,46$ & $286.957,46$ & $292.957,46$ & $286.957,46$ \\
\hline - Beli Bakalan Sapi & 4.780 .000 & 4.780 .000 & 4.780 .000 & 4.790 .000 & 4.780 .000 \\
\hline $\begin{array}{l}\text { - Biaya Pakan } \\
\text { - Biaya Obat-Obatan }\end{array}$ & $\begin{array}{l}1.322 .000 \\
100.033 .33\end{array}$ & $\begin{array}{l}1.322 .000 \\
100033.33\end{array}$ & $\begin{array}{l}1.325 .000 \\
100.033 .33\end{array}$ & 1.330 .000 & 1.322 .000 \\
\hline - Tenaga Kerja & 5.600 .000 & 5.760 .270 & 5.760 .270 & & hes \\
\hline $\begin{array}{l}\text { - Biaya lain-lain } \\
\text { (transportasi, listrik, } \\
\text { obat nyamuk, dll) }\end{array}$ & 213.666 & 213.666 & 213.666 & 222.670 & 209.666 \\
\hline Total Outflow & $14.603 .033,33$ & $15.072 .824,33$ & $15.542 .615,33$ & $16.012 .406,33$ & $16.482 .197,33$ \\
\hline
\end{tabular}

Rp 5000/10kg. Selain itu ada beberapa peternak yang menggunakan tetes tebu/amulase sebagai campuran pakan dengan harga Rp 10.000/botol. Setiap harinya sapi diberi dedak sebanyak 3-4 $\mathrm{kg}$ dengan dicampurkan dengan sedikit air. Pakan yang tidak mengeluarkan biaya yaitu pakan hijauan seperti rumput liar, rumput gajah, tebon, redheng kedelai dan lain-lain, karena tersedia melimpah ruah. Kesehatan ternak merupakan salah satu faktor penting yang mempengaruhi produksi ternak termasuk produksi daging sapi. Sapi - sapi potong yang dipelihara harus dilakukan vaksinasi dan sanitasi kandang untuk produksi daging yang optimal. Biaya kesehatan terdiri dari biaya untuk membeli obat cacing seharga Rp 500/1 kaplet, pembelian vitamin B kompleks seharga Rp 1.000/kaplet. Ada beberapa petani di Desa Napis, yang mengeluarkan biaya membayar dukun sapi. Masyarakat di Desa Napis sebagian masih percaya dukun daripada dokter hewan, hal ini juga dikarenakan akses jalan yang tidak memadai sehingga mantra hewan yang bertugas tidak sampai pada dusun-dusun yang sulit untuk diakses. Biaya yang dikeluarkan peternak untuk membayar dukun tersebut adalah $\mathrm{Rp}$ 10.000/setiap sapi sakit.

Komponen biaya terbanyak yang dikeluarkan peternak adalah biaya tenaga kerja. Biaya tenaga kerja tersebut terdiri dari mencari pakan, member pakan, membersihkan kandang dan membeli pakan. Biaya tenaga kerja ratarata peternak adalah sebesar $\mathrm{Rp}$ 5.700.000/tahun. Asumsi dari biaya tenaga kerja dihitung dari lama waktu yang dibutuhkan untuk mengelola usaha sapi potong. Biaya tenaga kerja dalam penelitian ini, telah diperhitungkan di dalam upah tenaga kerja. Upah tenaga kerja dihitung berdasarkan upah 
tenaga kerja regional usahatani di Desa Napis yaitu $\mathrm{Rp} 20.000 / 8 \mathrm{jam}$.

Selain biaya variabel dan biaya tetap, ada biaya penyusutan yang dikeluarkan oleh peternak namun biaya tersebut masuk dalam cash flow. Biaya penyusutan terdiri dari penyusutan kandang, penyusutan alat-alat, dan biaya penyusutan sumber air/pompo. Rata-rata biaya penyusutan yang dikeluarkan oleh peternak adalah sebesar Rp 186.202,54/tahun. Untuk lebih jelasnya dapat dilihat pada Tabel 1.

\section{Inflow Usaha Penggemukan Sapi Potong}

Faktor finansial menjadi tolok ukur utama dari suatu analisis usaha, terutama cash flow yang terjadi selama kegiatan usaha berjalan. Perhitungan besarnya biaya, keuntungan yang diperoleh dan harga jual pokok penjualan dilakukan untuk mengetahui indikator kelayakan suatu usaha. Indikator yang sering dipergunakan untuk melihat tingkat kelayakan suatu usaha adalah analisis rasio $\mathrm{B} / \mathrm{C}$, payback period (PBP), dan analisis titik impas atau break even point (BEP), selain itu, akan lebih baik jika dilengkapi dengan perhitungan net present value (NPV), dan internal rate of return (IRR) (Makkan,et al, 2014).

Penerimaan usaha ternak sapi potong di Desa Napis, didapat melalui penjualan ternak sapi yang telah mengalami proses penggemukan selama kurang lebih 4 bulan. Jumlah sapi potong yang digemukan oleh peternak adalah 30 sapi potong, sehingga setiap responden memiliki 1 sapi yang dikhususkan untuk digemukkan. Harga jual per kilogram berat hidup adalah $\mathrm{Rp} 28.000 /$ berat hidup, dengan berat akhir rata-rata sapi adalah 325,86 $\mathrm{kg}$. maka penerimaan rata-rata yang didapat petani dari hasil penjualan sapi adalah $\mathrm{Rp}$ 18586666.67/ tahun dengan dua kali penjualan dalam setahun.

\section{Analisis Indikator Kelayakan}

Untuk mengetahui besarnya net cash yang dapat memberikan gambaran mengenai jumlah dana yang tersedia digunakan analisis cash flow. Dengan analisis cash flows dapat diketahui B/C, NPV dan IRR. Pada tahun ke satu penggemukan sapi potong di Desa Napis proceeds nya masih minus karena pada tahun tersebut usaha penggemukan sapi potong masih harus mengeluarkan modal investasi sebesar Rp 15.000.000 dan belum memungkinkan untuk menghasilkan inflow. Pada tahun kedua sampai pada tahun kelima proceeds yang dihasilkan sudah semakin besar untuk tahun kedua $\mathrm{Rp}$ 3.984.229.01, tahun ketiga Rp 4.028.411,01, tahun keempat Rp 4.072.593, 01 dan tahun kelima adalah $\mathrm{Rp}$ 4.168.775,01. Untuk lebih jelasnya analisis cash flow dapat dilihat pada lampiran 2.

Evaluasi kelayakan usaha pada penelitian ini dilakukan untuk jangka waktu selama lima tahun. Hasil analisis kelayakan finansial usaha penggemukan di Kabupaten Bojonnegoro selama 5 tahun yaitu nilai BCR sebesar 1,23 yang berarti bahwa usaha penggemukan sapi potong layak diusahakan karena peternak mendapatkan keuntungan dari usaha tersebut. Selanjutnya nilai NPV=0 mengisyaratkan bahwa segala pengeluaran yang terjadi selama umur usaha telah dapat dikembalikan/diterima. NPV nilai NPV adalah sebesar Rp 481.110,59 yang berarti bahwa keuntungan yang diperoleh lebih besar daripada biaya produksi ditambah investasi. NPV positif berarti proyek tersebut menghasilkan lebih banyak kas dari yang dibutuhkan untuk menutup utang dan memberikan pengembalian yang diperlukan kepada pemodal.

Hasil perhitungan analisis IRR pada usaha pengemukan sapi potong ditunjukan pada lampiran 4. Dengan menggunakan tingkat bunga $10 \%$ dan $23 \%$, nilai sekarang (present value) arus kas (proceeds), yaitu berturut-turut sebesar Rp 13.385.717,71 dan minus $\mathrm{Rp}$ 17.253.591, 9. Dari hasil analisis tersebut diperoleh nilai IRR sebesar $11,30 \%$. Nilai IRR tersebut berarti bahwa pada tingkat bunga tersebut $(11,30 \%)$ nilai NPV sama dengan 0 . Berarti bahwa nilai IRR lebih besar dari besarnya discount factornya, sehingga usaha penggemukan sapi di Desa Napis, Kecamatan Tambakrejo, Kabupaten Bojonegoro layak untuk diusahakan. Tingkat bunga yang menjadikan nilai $\mathrm{NPV}=0$ tersebut mengindikasikan bahwa nilai ekspektasi investor investor akan tingkat pengembalian investasinya. Kemudian kriteria selanjutnya adalah Pay Back Periode yang hasilnya menunjukan bahwa waktu yang dibutuhkan untuk mengembalikan investasi adalah 2 tahun 9 bulan. Nilai break even point yang diperoleh adalah untuk BEP unit sebesar 86,09 Kg yang berarti bahwa peternak tidak akan rugi maupun untung ketika melakukan usaha penggemukan 
sapi potong dengan pertambahan berat penggemukan adalah $86,09 \mathrm{~kg}$ berat hidup sapi. Sedangkan nilai BEP harga diperoleh sebesar $\mathrm{Rp}$ 2.207.649,716, yang mengindikasikan bahwa peternak yang menjual sapi potongnya seharga Rp 2.207.649,716 berada pada kondisi tidak rugi dan tidak untung.

\section{KESIMPULAN DAN SARAN}

Berdasarkan hasil penelitian dapat disimpulkan bahwa usaha penggemukan sapi potong di Desa Napis, Kecamatan Tambakrejo, Kabupaten Bojonegoro yang dilaksanakan dengan jangka waktu 5 tahun setelah dianalisis dengan menggunakan discount factor $10 \%$ menghasilkan BCR 1,23, niai NPV positif sebesar Rp 481.110, 59 dan nilai IRR sebesar $11,30 \%$, . Dilihat dari nilai BCR, NPV yang dihasilkan usaha penggemukan sapi potong ini layak untuk dijalankan. Namun jika dilihat dari nilai IRR menggunakan discount factor $15 \%$ $20 \%$ maka usaha sapi potong belum layak untuk diusahakan. Keuntungan kumulatif selama 5 tahun adalah sebesar Rp. 5.252.074,99. Selain itu diperoleh nilai pay back periode adalah 2,8 , yang berarti bahwa usaha penggemukan sapi potong tidak perlu waktu yang lama untuk mengembalikan modal yaitu selama 2 tahun 9 bulan modal dan investasi akan kembali.

Berdasarkan hasil penelitian dapat disarankan kepada Pemerintah Kabupaten Bojonegoro agar dapat melakukan pendampingan dan mengarahkan peternak untuk melakukan usaha penggemukan karena layak untuk diusahakan, Selain itu juga diharapkan agar pemerintah Kabupaten Bojonegoro memberikan bantuan kepada peternak terkait permodalan mengingat masih sedikit peternak yang mengusahakan ternaknya dalam skala yang besar. Selanjutnya diperlukan penelitian lanjutan mengenai analisis nonfinansial yang meliputi aspek pasar, aspek teknis, aspek manajemen, aspek hukum, aspek sosial, ekonomi, budaya dan aspek lingkungan. Kajian mengenai aspek nonfinansial akan melengkapi analisis finansial yang akan mendukung analisis studi kelayakan usaha penggemukan sapi potong.

\section{DAFTAR PUSTAKA}

Tim Penulis Agriflo. 2012. Sapi dari Hulu ke Hilir. Jakarta : Penebar Swadaya Group.

[BPS] Badan Pusat Statistik. 2014. Statistik Bojonegoro. Jawa Timur : Badan Pusat Statistik.

Direktorat Jendral peternakan. 2012. Statistik Peternakan. Direktorat Jendral Peternakan, Jakarta

Direktorat Jendral peternakan. 2014. Statistik Peternakan. Direktorat Jendral Peternakan, Jakarta.

Halim, Abdul. 2009. Analisis Kelayakan Investasi Bisnis, Kajian dari Aspek Keuangan. Graha Ilmu. Yogyakarta.

Jumingan. 2009. Studi Kelayakan Bisnis. Teori \& Pembuatan Proposal Kelayakan. Yustianti F, editor. Jakarta (ID): Bumi Aksara.

Gray, C., Simanjuntak, P., Sabur, L.K., and Maspaitella, F.P.L., 2005. Pengantar Evaluasi Proyek. Gramedia Pustaka Utama. Jakarta.

Kadariah, Karlina L, Gray C. 1999. Pengantar Evaluasi Proyek. Jakarta (ID): Universitas Indonesia.

Kreuter UP dan Workman JP. 1994. Government Policy Effects on Cattle and Wildlife ranching profits in Zimbabwe. Journal of Range Management Vol.47 Halaman 264-269 Juli 1994

Makkan, Annie, Elly, dan Lumenta. 2014. Analisis Keuntungan Penggemukan Sapi Potong Kelompok Tani "Keong Mas" Desa Tambulango Kecamatan Sangkub Bolaang Mongondow Utara (studi Kasus). Jurnal Zootek Vol 34 No.1 2836.

Matatula, Michel Johan. 2010. Analisis Finansial Usaha Peternakan Sapi Potong Pola Gaduhan di Kecamatan Kairatu Kabupaten Seram Bagian Barat. Jurnal Agroforestri Vol.V Nomor 3 September 2010. 
Retna D. L., Lukman M. Baga dan Rita N.: Analisis Keuntungan Finansial ...

Rochadi, Sulaeman T, Udiantono TS. 1993. Strategi Pengembangan Industri Peternakan Sapi Potong Berskala Kecil dan Menengah. PPA, CIDES, UQ. Penerbit Bangkit. Jakarta.

Soehadji, 1995. Peluang usaha sapi potong. Makalah disampaikan pada seminar Nasional Industri Peternakan Rakyat sapi potong di Indonesia, di Bandar Lampung Ditjen Peternakan . Jakarta

Widiyazid I, Parwati NS, Guntoro S dan Yasa R. 1999. Analisis usahatani penggemukan sapi potong dalam berbagai masukan teknologi. Proseding Seminar Nasional Teknologi Peternakan dan Veteriner. Pusat Penelitian dan Pengembangan Peternakan. Bogor. Hal: 475-485.

Zulfanita, Wiguna A, dan Nurtini. 2009. Evaluasi Kelayakan Usaha Penggemukan Sapi Potong Gaduhan di Desa Grantung Kecamatan Bayan Kabupaten Purworejo. Buletin Peternakan Vol.33 (1), 57-63. 
Retna D. L., Lukman M. Baga dan Rita N.: Analisis Keuntungan Finansial ...

Lampiran 1.Tabel Laba-Rugi

\begin{tabular}{lrrrrrr}
\hline \multirow{2}{*}{ Keterangan } & \multicolumn{5}{c}{ Tahun ke- } & \\
\cline { 2 - 6 } & \multicolumn{1}{c}{$\mathbf{1}$} & \multicolumn{1}{c}{$\mathbf{2}$} & \multicolumn{1}{c}{$\mathbf{3}$} & \multicolumn{1}{c}{$\mathbf{4}$} & \multicolumn{1}{c}{$\mathbf{5}$} & Jumlah \\
\hline Penjualan & $18,586,667$ & $19,266,667$ & $19,946,667$ & $20,656,667$ & $21,378,667$ & $99,835,333$ \\
Biaya & & & & & & \\
Biaya Tetap (Rp) & 473,160 & 633,430 & 799,457 & 995,484 & $1,151,511$ & $4,053,042$ \\
Biaya Variabel (Rp) & $14,603,033$ & $15,072,824$ & $15,542,615$ & $16,012,406$ & $16,482,197$ & $77,713,077$ \\
Total Biaya (Rp) & $15,076,193$ & $15,706,254$ & $16,342,072$ & $17,007,890$ & $17,633,708$ & $81,766,119$ \\
Laba Kotor (Rp) & $3,510,473$ & $3,560,412$ & $3,604,594$ & $3,648,776$ & $3,744,958$ & $18,069,215$ \\
Depresiasi (Rp) & $2,563,428$ & $2,563,428$ & $2,563,428$ & $2,563,428$ & $2,563,428$ & $12,817,140$ \\
Laba sebelum Pajak (Rp) & 947,045 & 996,984 & $1,041,166$ & $1,085,348$ & $1,181,530$ & $5,252,075$ \\
\hline
\end{tabular}

Lampiran 2. Tabel Aliran Cash Flow

\begin{tabular}{|c|c|c|c|c|c|c|}
\hline \multirow{2}{*}{ Keterangan } & \multicolumn{5}{|c|}{ Tahun ke- } & \multirow[b]{2}{*}{ Jumlah } \\
\hline & 1 & 2 & 3 & 4 & 5 & \\
\hline Investasi (Rp) & $15,000,000.00$ & & & & & \\
\hline Biaya Tetap dan Variabel (Rp) & $15,076,193.32$ & $15,706,254.32$ & $16,342,072.32$ & $17,007,890.32$ & $17,633,708.32$ & $81,766,118.61$ \\
\hline Total Pengeluaran & $30,076,193.32$ & $31,920,970.00$ & $32,556,788.00$ & $33,222,606.00$ & $33,848,424.00$ & $161,624,981.32$ \\
\hline Penerimaan & $18,586,666.67$ & $19,266,666.67$ & $19,946,666.67$ & $20,656,666.67$ & $21,378,666.67$ & $99,835,333.33$ \\
\hline Proceeds & -11489526.66 & $3,984,229.01$ & $4,028,411.01$ & $4,072,593.01$ & $4,168,775.01$ & $20,171,298.05$ \\
\hline Laba Kotor & $3,510,473.34$ & $3,560,412.34$ & $3,604,594.34$ & $3,648,776.34$ & $3,744,958.34$ & $18,069,214.72$ \\
\hline Depresiasi & $2,563,427.95$ & $2,563,427.95$ & $2,563,427.95$ & $2,563,427.95$ & $2,563,427.95$ & $12,817,139.73$ \\
\hline Laba Sebelum Pajak & $947,045.40$ & $996,984.40$ & $1,041,166.40$ & $1,085,348.40$ & $1,181,530.40$ & $5,252,074.99$ \\
\hline PayBack Periode & & -15473755.67 & $8,012,640.02$ & $8,101,004.02$ & $8,241,368.02$ & $8,881,256.40$ \\
\hline NPV & -10445024.23 & $3,292,751.25$ & $2,751,458.92$ & $2,528,759.84$ & $2,353,164.81$ & $481,110.59$ \\
\hline $\mathrm{R} / \mathrm{C}$ & 1.23 & & & & & \\
\hline BEP Produksi & 86.09 & & & & & \\
\hline BEP (Rp) & $2,207,649.72$ & & & & & \\
\hline
\end{tabular}

Lampiran 3.Tabel IRR

\begin{tabular}{cllrrr}
\hline Tahun & proceeds & df $\mathbf{1 0} \%$ & pv proceeds & \multicolumn{1}{c}{ df $\mathbf{2 3 \%}$} & \multicolumn{1}{c}{ pv proceeds } \\
\hline 1 & -11082709.99 & 0.909090909 & -10075190.9 & 0.81300813 & -8191212.113 \\
2 & 3984229.011 & 0.826446281 & 3292751.249 & 0.66098222 & 2176450.029 \\
3 & 4028411.011 & 0.751314801 & 3026604.817 & 0.537383918 & 1626448.756 \\
4 & 4072593.011 & 0.683013455 & 2781635.825 & 0.436897495 & 1215289.723 \\
5 & 4168775.011 & 0.620921323 & 2588481.295 & 0.355201215 & 919431.7014 \\
& & & 13385717.71 & & -17253591.9 \\
\hline
\end{tabular}

